\title{
Case Report: Guillain-Barre Syndrome Due to Tramadol
}

\author{
Ali Banagozar Mohammadi ${ }^{1}$, Ali Ostadi ${ }^{1}$ (D), Maryam Paeezi ${ }^{2^{*}}$ (D), Babak Mostafazadeh ${ }^{3}$ \\ 1. Department of Internal Medicine, School of Medicine, Tabriz University of Medical Sciences, Tabriz, Iran. \\ 2. Department of Forensic Medicine and Toxicology, Loghman Hakim Hospital, School of Medicine, Shahid Beheshti University of Medical Sciences, \\ Tehran, Iran. \\ 3. Toxicological Research Center, Shahid Beheshti University of Medical Sciences, Tehran, Iran.
}

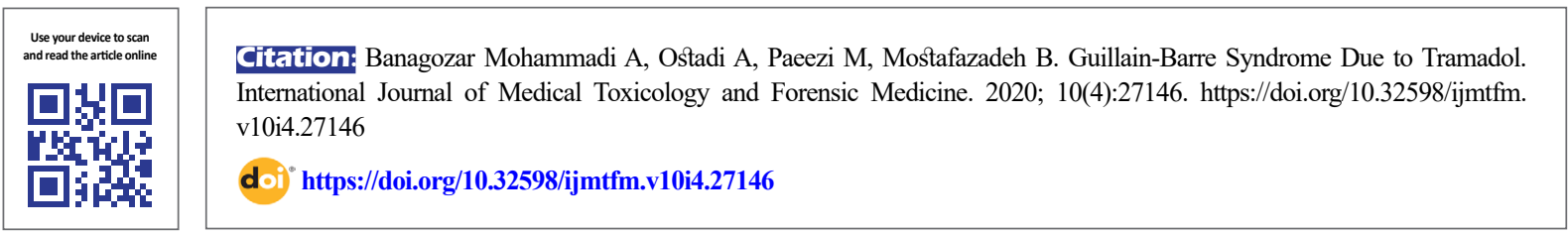

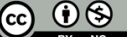

Article info:

Received: 18 Sep 2019

First Revision: 04 Nov 2019

Accepted: 10 Jan 2020

Published: 22 Dec2020

\section{Keywords:}

Tramadol, Gillian-Barre syndrome, Reactive oxygen species, Seizure

\section{ABSTRACT}

Tramadol is a powerful prescription medication used for pain relief of varying intensities. Tramadol was initially produced in Germany to alleviate postsurgical and chronic pains. We describe a case of a 22-year-old male with no past medical history who took tramadol for the second time and then had a tonic-clonic seizure episode that worsened the weakness of his inferior limbs and followed by loss of consciousness. According to physical examination, clinical and paraclinical tests, he was diagnosed with Guillain-Barre syndrome. After treatment with intravenous immunoglobulin, he was improved and discharged 9 days after treatment. He was recommended to continue physiotherapy. The relation between tramadol using and GuillainBarre syndrome development is unknown but it can be due to reactive oxygen species generation.

\section{Case Presentation}

$\mathbf{W}$

e were presented with a case of a 22-year-old male with no past medical history. His only positive history was taking one $200 \mathrm{mg}$ tramadol tablet 20 days earlier which was followed by seizure and then quadriplegia. He did not refer to any medical center or receive any medical care. He took another tablet of tramadol on the day of admission. He had a tonic-clonic seizure episode that worsened the weakness of his inferior limbs and he then lost his consciousness. He was taken to a local hospital and intubated before he was referred to our Toxicology Center due to loss of consciousness and respiratory distress. He was admitted to the intensive care unit with a tramadol toxicity diagnosis in our center.

Early after hospitalization, his vital signs were taken ( $\mathrm{HR}=83$ beats/minute, $\mathrm{BP}=100 / 74 \mathrm{~mm} \mathrm{Hg}, \mathrm{T}=37.2^{\circ} \mathrm{C}$ ). He did not respond to pain, light, and sound. His Glasgow coma scale was 6 out of 15 , so precise evaluation of cen-

\section{* Corresponding Author:}

Maryam Paeezi, MD.

Address: Department of Forensic Medicine and Toxicology, Loghman Hakim Hospital, School of Medicine, Shahid Beheshti University of Medical Sciences, Tehran, Iran.

Tel: +98 (914) 4192232

E-mail: mpaeezi47@gmail.com 
tral and peripheral nervous systems and muscle forces was not possible in advance. Brain CT scan, brain, and cervical MRI were normal in imaging studies. The cerebrospinal fluid analysis was normal too. His consciousness level was raised and he was extubated on the second day of hospitalization without respiratory distress or swallowing problems.

In the examination, his deep tendon reflexes of four limbs had been decreased, muscle forces were two out of five.

Four limbs EMG-NCV study was done and reported acute severe peripheral sensorimotor neuropathy with mixed demyelinating and axonal loss nature.

Other abnormal paraclinical findings were Aspartate transaminase $(A S T)=296\left(1^{\text {st }}\right)>48\left(7^{\text {th }}\right)$, alanine transaminase $(A L T)=657\left(1^{\text {st }}\right)>178\left(7^{\text {th }}\right)$, Creatinine kinase $=134\left(1^{\text {st }}\right)$ $>32\left(5^{\text {th }}\right)$, Lactic Dehydrogenase $(\mathrm{LDH})=654\left(1^{\mathrm{st}}\right)>420\left(5^{\text {th }}\right)$.

Liver sonography and viral markers were normal.

Neurology consultation was requested and he was diagnosed with Guillain-Barre syndrome based on physical examination and electrodiagnostic findings. Immunoglobulin was indicated $25 \mathrm{~g} / \mathrm{d}$ for four days and $30 \mathrm{~g}$ on the fifth day. Simultaneously physiotherapy of limbs was done. Besides, he received gabapentin, vitamin B1 orally.

IgA serum level in second day was $143 \mathrm{mg} / \mathrm{dL}$ (normal range: $70-400 \mathrm{mg} / \mathrm{dL}$ ).

Muscle forces increased four days after Immunoglobulin administration (upper limbs 4/5, lower limbs 3/5). He improved and was discharged 9 days after treatment and was recommended to continue physiotherapy.

\section{Discussion}

Tramadol with its opioid and non-opioid properties is vastly used in the relief of mild to moderate pain and is a centrally acting analgesic [1]. It is known that tramadol has a low affinity for $\mu$ - and $\kappa$-opioid receptors and also suspends the reuptake of both norepinephrine and serotonin (5-hydroxytryptamine) neurotransmitters [2]. It invigorates the dopamine (D2) receptors and also inhibits the gamma-aminobutyric acid release in the central nervous system [3, 4]. Moreover, it has some N-methyl-Daspartate antagonistic properties [5, 6]. Tramadol has been listed in Iran's national drug list since 2003 [7]. There has been a rise in tramadol overdose, misuse, and abuse in Iran [8-10]. The prominent effects of tramadol misuse include nausea, dizziness, somnolence, drowsiness, increased sweating, vomiting, and dry mouth $[11,12]$. The two main drug reactions which are considered to be life-threatening are seizure and apnea, and these alarming symptoms can be seen in therapeutic and toxic doses $[8,10,13]$.

Many adverse effects and complications in acute and chronic tramadol use were reported.

According to Le Berre et al. research, tramadol induced hyponatremia as a consequence of inappropriate antidiuretic hormone secretion [14]. Liver and kidney function tests disorders such as AST, ALT, and LDH level rising was seen in some studies [15-17].

Tramadol can trigger seizure episodes, especially with high doses, or if it is accompanied by the use of medicines that lower the seizure threshold. A high risk of developing serotonin syndrome has been seen in people who use tramadol with serotonergic medicines. To minimize the risk of developing such cases, the lowest possible dose should be prescribed and in cases, with a history of seizure prescribing, tramadol must be avoided. It is advisable to use other analgesics instead of tramadol in patients with a history of seizures or serotonin syndrome [18]. in our case, he had no additional, seizure, or medical history. He was diagnosed with GBS after taking tramadol. There has not been any report of Guillain-Barre's development after tramadol taking or after seizure yet.

Once the immune system damages the peripheral nervous system, one may develop Guillain-Barre syndrome. Early symptoms normally include changes in sensation or pain accompanied by muscle weakness, starting in the feet and hands. It usually spreads to the arms and upper body, engaging both sides. The symptoms progress over hours to a few weeks [19]. This disorder can be life-threatening during the acute phase since statistically, $15 \%$ of patients are at risk of developing weakness of the breathing muscles requiring mechanical ventilation [20].

Some patients suffer changes in the function of the autonomic nervous system leading to dangerous abnormalities in heart rate and blood pressure [19]. It is yet unknown as to why this occurs [19]. This reaction involves an autoimmune disorder such that the body's immune system mistakenly attacks the peripheral nerves damaging their myelin insulation [19]. In some cases, the cause of this immune dysfunction includes an infection or less commonly due to surgery and rarely by vaccination $[19,20]$. In this case, the cause of Guillain-Barre's development after tramadol taking and then seizure is unknown too.

Using the exclusion method, with the support of tests such as nerve conduction studies and examination of the cerebro- 
spinal fluid, the diagnosis is usually made along with examining signs and symptoms [19]. A frequent expression of posterior reversible encephalopathy syndrome in the background of Guillain-Barre syndrome is epileptic seizures.

Hinchery et al. were first to describe this clinicoradiological entity with the exact wording of reversible posterior leukoencephalopathy syndrome [21].

There is likely a connection between the initiation and progression of epilepsy and oxidative stress resulting from excessive free-radical release $[22,23]$.

Various neurological disorders have been linked to oxidative stress through the shifts in the levels of reactive oxygen species and antioxidative parameters.

Mojdeh Ghabaee was able to demonstrate Antioxidant Activity (AOA) and malondialdehyde levels in people affected with Guillain-Barre syndrome. They concluded that in Guillain-Barre patients an imbalance between the levels of AOA and MDA in both CSF and serum can be detected [24]. Free radical toxicity may also be a factor in GBS patients [25].

Tramadol is metabolized by the cytochrome P450 system and as a result oxidative stress is induced in different organs [26]. Tramadol is metabolized by CYP3A4 and CYP2D6 into a more potent opioid analgesic metabolite M1 [27, 28]. Moreover, hepatotoxicity was increased by CYP2D6 gene polymorphisms by the accumulation of tramadol bioactive metabolite (M1) followed by oxidative stress induction [28, 29].

An individual's CYP genetics influences the opioid analgesic potency because people with poor metabolism have faced little conversion to the more active M1 opioid metabolite, whereas people with higher metabolic rates experience the greatest analgesic effects $[27,30]$.

\section{Conclusion}

According to the mentioned information, reactive oxygen species generation due to tramadol using and also seizure could have been the cause of developing GuillainBarre in our case. Also based on the CYP450s level of activity in individuals that metabolize tramadol, reactive oxygen species generation rates can be different from person to person. This hypothesis needs more investigation.

\section{Ethical Considerations}

\section{Compliance with ethical guidelines}

All ethical principles are considered in this article.

\section{Funding}

This research did not receive any grant from funding agencies in the public, commercial, or non-profit sectors.

\section{Author's contributions}

All authors contributed in preparing this article.

\section{Conflict of interest}

The authors declared no conflict of interest.

\section{Acknowledgements}

We would like to thank the Clinical Research Development Unit of Sina Educational, Research and Treatment Center, Tabriz University of Medical Sciences for their help.

\section{References}

[1] Rahimi HR, Soltaninejad K, Shadnia S. Acute tramadol poisoning and its clinical and laboratory findings. J Res Med Sci. 2014; 19(9):855-9. [PMID] [PMCID]

[2] Grond S, Sablotzki A. Clinical pharmacology of tramadol. Clin Pharmacokinet. 2004; 43(13):879-923. [DOI:10.2165/00003088-200443130-00004] [PMID]

[3] Nakamura A, Narita M, Miyoshi K, Shindo K, Okutsu D, Suzuki M, et al. Changes in the rewarding effects induced by tramadol and its active metabolite M1 after sciatic nerve injury in mice. Psychopharmacology (Berl) 2008; 200(3):307-16. [DOI:10.1007/s00213-008-1180-1] [PMID]

[4] Rehni AK, Singh I, Kumar M. Tramadol-induced seizurogenic effect: A possible role of opioid-dependent gamma-aminobutyric acid inhibitory pathway. Basic Clin Pharmacol Toxicol. 2008; 103:262-6. [DOI:10.1111/j.17427843.2008.00276.x] [PMID]

[5] Nagakannan P, Shivasharan BD, Thippeswamy BS, Veerapur VP. Effect of tramadol on behavioral alterations and lipid peroxidation after transient forebrain ischemia in rats Toxicol Mech Methods. 2012; 22(9):674-8. [DOI:10.3109/15 376516.2012.716092] [PMID]

[6] Chaparro LE, Wiffen PJ, Moore RA, Gilron I. Combination pharmacotherapy for the treatment of neuropathic pain in adults. Cochrane Database Syst Rev. 2012; 2012(7):CD008943. [DOI:10.1002/14651858.CD008943.pub2] [PMID] [PMCID]

[7] Gholami K, Shalviri G, Zarbakhsh A, Daryabari N, Yousefian $S$. New guideline for tramadol usage following adverse 
drug reactions reported to the Iranian Pharmacovigilance Center. Pharmacoepidemiol Drug Saf. 2007; 16(2):229-37. [DOI:10.1002/pds.1331] [PMID]

[8] Shadnia S, Soltaninejad K, Heydari K, Sasanian G, Abdollahi M. Tramadol intoxication: A review of 114 cases. Hum Exp Toxicol. 2008; 27(3):201-5. [DOI:10.1177/0960327108090270] [PMID]

[9] Shadnia S, Brent J, Mousavi-Fatemi K, Hafezi P, Soltaninejad K. Recurrent seizures in tramadol intoxication: Implications for therapy based on 100 patients. Basic Clin Pharmacol Toxicol. 2012 111(2):133-6. [DOI:10.1111/j.1742-7843.2012.00874.x] [PMID]

[10] Hassanian-Moghaddam H, Farajidana H, Sarjami S, Owliaey H. Tramadol-induced apnea. Am J Emerg Med. 2013; 31(1):26-31. [DOI:10.1016/j.ajem.2012.05.013] [PMID]

[11] Götrick B, Tobin G. The xerogenic potency and mechanism of action of tramadol inhibition of salivary secretion in rats. Arch Oral Biol. 2004; 49(12):969-73. [DOI:10.1016/j.archoralbio.2004.07.007] [PMID]

[12] Rawal N, Macquaire V, Catalá E, Berti M, Costa R, Wietlisbach M. Tramadol/paracetamol combination tablet for postoperative pain following ambulatory hand surgery: A doubleblind, double-dummy, randomized, parallel-group trial. J Pain Res. 2011; 4:103-10. [DOI:10.2147/JPR.S16760] [PMID] [PMCID]

[13] Jovanović-Cupić V, Martinović Z, Nesić N. Seizures associated with intoxication and abuse of tramadol. Clin Toxicol $(\mathrm{Ph}-$ ila) 2006; 44(2):143-6. [DOI:10.1080/1556365050014418] [PMID]

[14] Le Berre JP, Desramé J, Lecoules S, Coutant G, Béchade D, Algayres JP. [Hyponatremia due to tramadol (French)]. Rev Med Interne. 2007; 28(12):888-9. [DOI:10.1016/j. revmed.2007.06.011] [PMID]

[15] Wu WN, McKown LA, Liao S. Metabolism of the analgesic drug ULTRAM (tramadol hydrochloride) in humans: APIMS and MS/MS characterization of metabolites. Xenobiotica. 2002; 32(5):411-25. [DOI:10.1080/00498250110113230] [PMID]

[16] Panchenko LF, Pirozhkov SV, Nadezhdin AV, Baronets VIu, Usmanova NN. [Lipid peroxidation, peroxyl radicalscavenging system of plasma and liver and heart pathology in adolescence heroin users (Russian)]. Vopr Med Khim. 1999; 45(6):501-6. [PMID]

[17] Elmanama AA, Abu Tayyem NA, Esawwaf H, Hmaid I. Tramadol-induced liver and kidney toxicity among abusers in Gaza strip, Palestine. Jordan J Biol Sci. 2015; 8(2):133-7. [DOI:10.12816/0027559]

[18] Savage R. Serious reactions with tramadol: Seizures and serotonin syndrome. New Zealand Medicines and Medical Devices Safety Authority. 2007; 28(1):11-3. https://www. medsafe.govt.nz/profs/puarticles/TramSerious.htm

[19] Office of Communications and Public Liaison, National Institute of Neurological Disorders and Stroke, National Institutes of Health. Guillain-Barre syndrome fact sheet. Maryland: National Institute of Neurological Disorders and Stroke; 2016. https://www.ninds.nih.gov/Disorders/Patient-Caregiver-Education/Fact-Sheets/Guillain-Barr\%C3\%A9-Syndrome-Fact-Sheet

[20] Ferri FF. Ferri's Clinical Advisor 2017: 5 Books in 1. Amesterdam: Elsevier Health Sciences; 2016. https://www.amazon. com/Ferris-Clinical-Advisor-2017-Solutions/dp/032328048X
[21] Hinchey J, Chaves C, Appignani B, Breen J, Pao L, Wang A, et al. A reversible posterior leukoencephalopathy syndrome. N Engl J Med. 1996; 334(8):494-500. [DOI:10.1056/ NEJM199602223340803] [PMID]

[22] Shin EJ, Jeong JH, Chung YH, Kim WK, Ko KH, Bach JH, et al. Role of oxidative stress in epileptic seizures. Neurochem Int. 2011; 59(2):122-37. [DOI:10.1016/j.neuint.2011.03.025] [PMID] [PMCID]

[23] Aguiar CC, Almeida AB, Araújo PV, de Abreu RN, Chaves EM, do Vale OC, et al. Oxidative stress and epilepsy: Literature review. Oxid Med Cell Longev. 2012; 2012:795259. [DOI:10.1155/2012/795259] [PMID] [PMCID]

[24] Ghabaee M, Jabedari B, Al-E-Eshagh N, Ghaffarpour M, Asadi F. Serum and cerebrospinal fluid antioxidant activity and lipid peroxidation in Guillain-Barre syndrome and multiple sclerosis patients. Int J Neurosci. 2010; 120(4):301-4. [DOI:10.3109/00207451003695690] [PMID]

[25] Kumar KT, Chandrika A, Sumanth KN, Sireesha P, Rao $\mathrm{S}$, Rao A. Free radical toxicity and antioxidants in GuillainBarre syndrome, A preliminary study. Clin Chim Acta. 2004; 346(2):205-9. [DOI:10.1016/j.cccn.2004.03.032] [PMID]

[26] Sheweita SA, Almasmari AA, El-Banna SG. Tramadolinduced hepato- and nephrotoxicity in rats: Role of Curcumin and Gallic acid as antioxidants. PLoS One. 2018; 13(8):e0202110. [DOI:10.1371/journal.pone.0202110] [PMID] [PMCID]

[27] Miotto K, Cho AK, Khalil MA, Blanco K, Sasaki JD, Rawson R. Trends in Tramadol: Pharmacology, metabolism, and misuse. Anesth Analg. 2017; 124(1):44-51. [DOI:10.1213/ ANE.0000000000001683] [PMID]

[28] Dean L. Tramadol Therapy and CYP2D6 Genotype. In: Pratt VM, McLeod HL, Rubinstein WS, Scott SA, Dean LC, Kattman BL, et al., (editors). Medical Genetics Summaries [Internet]. Bethesda (MD): National Center for Biotechnology Information (US); 2012. [PMID]

[29] Arafa MH, Atteia HH. Genetic polymorphisms of cytochrome P450 2D6 (CYP2D6) are associated with long term tramadol treatment-induced oxidative damage and hepatotoxicity. Toxicol Appl Pharmacol. 2018; 346:37-44. [DOI:10.1016/j.taap.2018.03.019] [PMID]

[30] Raffa RB. Basic pharmacology relevant to drug abuse assessment: Tramadol as example. J Clin Pharm Ther. 2008, 33(2):101-8. [DOI:10.1111/j.1365-2710.2008.00897.x] [PMID] 